\title{
AI and the form of capital - Preliminary notes on the media culture of artificial intelligence
}

\author{
Jens Schröter, Christoph Ernst
}

Recently there is much talk about the coming possibilities of "Artificial Intelligence" or "Robotics". But these technological developments are embedded in a media culture. The recent data surge is at once the precondition for machine learning as is the analysis of this data one of the goals of AI-research. The economic and ideological forms of society shape the media culture of AI. In this essay, we try to sketch these implications for understanding AI as a central topic of recent digital media culture.

Keywords: Artificial Intelligence, Robotics, Media Culture, Capitalism, Ideology 
At the moment there is a central topic in the mass media and that is, of course, the so-called "digitization". Somehow everything seems to become "digital" and somehow this will bring about big changes. Even more conspicuous, however, is the fact that in this, sometimes confusing, discussion there is an increasingly prominent strand that revolves around a particular form of digital technology: so-called "artificial intelligence" (= AI) and - which is by no means the same, but can belong together and mostly appears in one discursive formation - so-called "robotics". The Frankfurter Allgemeine Zeitung of September 6th wrote: "Artificial intelligence is considered one of the most important trends in the corporate world". On several occasions, it was predicted that autonomous robots will soon become part of everyday life, and there are fears that large numbers of jobs could be at risk (whether or not these complaints are justified).

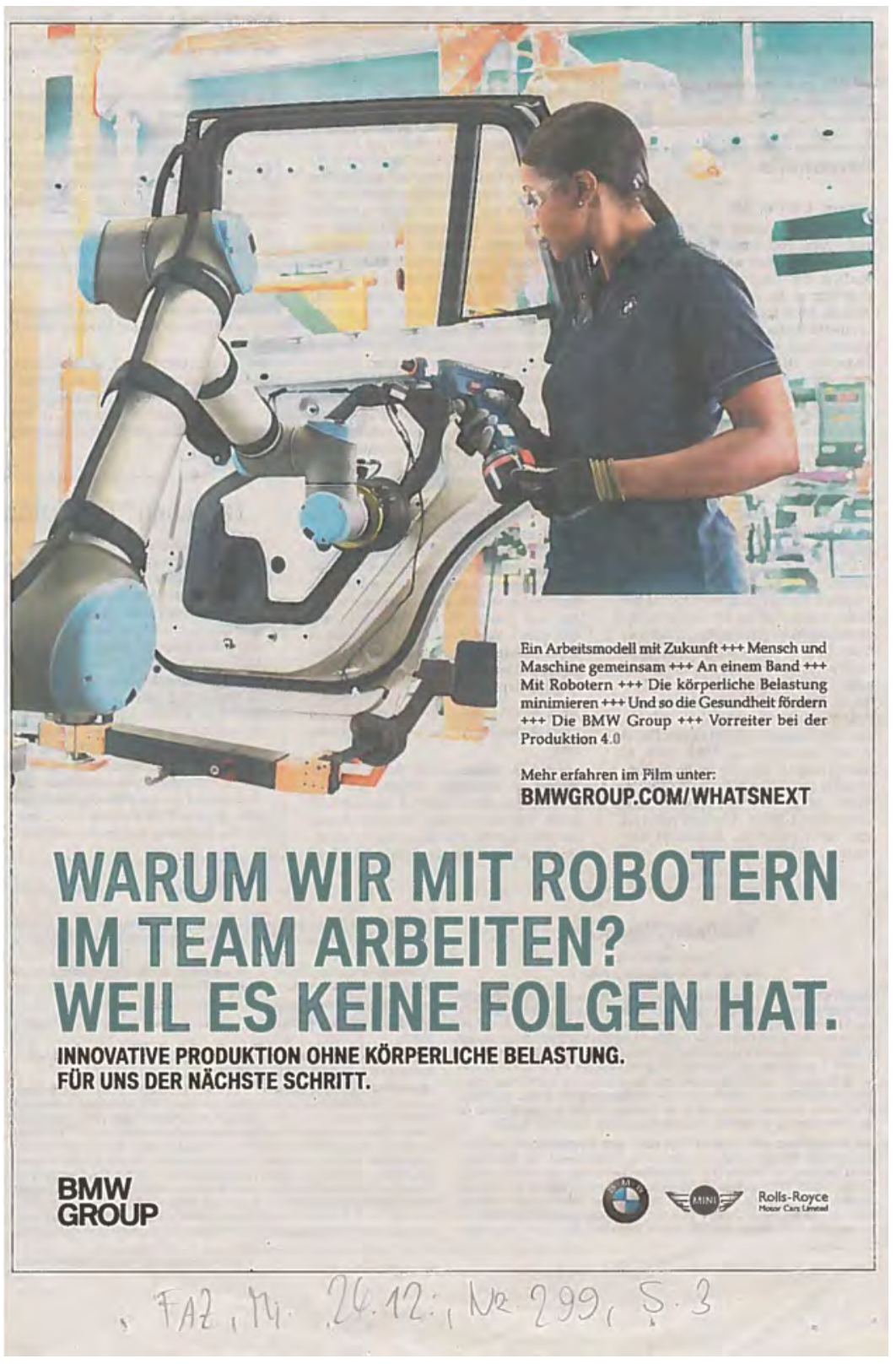

[Fig. 1] BMW Advertisement (Source: Frankfurter Allgemeine Zeitung, 24.12., Nr. 299, p. 3) 
Here you can see an advertisement of the BMW Group claiming that their product has "no consequences" - for advertising quite unusual - and emphasizes that "man and machine work together". Such advertising reacts, although it is primarily concerned with the "physical strain", apparently already to the fears that the spread of such systems could fundamentally call the "working society" into question. Through technologies such as Alexa, forms of artificial intelligence could soon move into the families. But can AI be addressed as part of media culture at all?

In the following, we would like to ask how to approach the media culture of artificial intelligence. We will do this in three steps. 1) First of all, we would like to draw on a media theory that dealt with the question of artificial intelligence at least marginally: Friedrich Kittler's media archaeology. It allows to give artificial intelligence a place in media history and can explain why the AI has been so prominent in recent years. However, as a media theory, Kittler's theory tries to explain this process immanently from the logic of the media. But through this media-techno-logical immanence, however, the question of the connection between the media culture under investigation and other social phenomena seems to be lost - social phenomena that are implied by the BMW advertisement shown (e.g. discussions about the future of work). 2) In the second part, the question of $A I$ is therefore linked to the question of the social form of society, which leads to a fundamental discussion of the concept of media culture. In 3) a brief summary is given.

\section{AI as a medium?}

Friedrich Kittler's essay "History of Communication Media" ends with the sentence:

Without reference to the individual or to mankind, communication technologies will have overhauled each other until finally an artificial intelligence proceeds to the interception of possible intelligences in space. (Kittler 1996)

First of all, a certain theoretical model of the history of media is presented: Communication technologies, here Kittler's word for media, are "escalating" autonomously, they respond to each other, Kittler gives an example elsewhere:

In a strategic chain of escalation, the telegraph appeared in order to surpass the speed of messenger postal services; radio was developed to solve the problem of vulnerable undersea cables; and the computer emerged to make possible the codification of secret and interceptable - radio communications. (Kittler 1999)

Kittler includes the (coming) artificial intelligence(s) in media history. With Kittler's famous and controversial - definition of "media technologies", AI can be described as technologies of "transmission, storage, and processing of information" (Kittler 1993, 8), insofar as it stores and processes information. The point is that artificial intelligence should be able to process information independently and come to its own conclusions, which are above all unpredictable. For example, the textbook on the artificial intelligence by Lämmel and Cleve defines an autonomous system like this: "An agent acts independently in fulfilling the tasks transferred. Autonomous decisions are made regarding the actions to be carried out in detail" (Lämmel and Cleve 2008, 22). An example that has caused quite a stir lately was Alpha Go's victory over Lee Sedol: "AlphaGo makes moves that a human being would never make," (Stöcker 2016) said professional player Young Sun Yoon in an interview with Spiegel Online. 
Kittler's strange reference to alien intelligence can thus be understood as a metaphor to underline the AI's unpredictable foreignness.

The classification of AI into the logic of the media is helpful because it could explain what AI is all about right now. If one reads Kittler's statement on escalation again:

In a strategic chain of escalation, the telegraph appeared in order to surpass the speed of messenger postal services; radio was developed to solve the problem of vulnerable undersea cables; and the computer emerged to make possible the codification of secret and interceptable - radio communications. (Kittler 1999)

...this escalation could be continued with the phrase:... 'and new AI developments have emerged to search, organize and analyze the vast amounts of data accumulated with computers and their sensors'. Ethem Alpaydin notes in his book Machine Learning: The New $A I$ quite explicitly that it is the "data surge [...] that is mainly responsible for triggering the widespread interest in data analysis and machine learning" (Alpaydin 2016, x). To just say that $\mathrm{AI}$ is now more intensively researched because the computing power is available, is not enough. You could use the computing power in a different way. And indeed, traces of this problem can be found in media culture. In an article titled "Opaque Intelligences" again in the Frankfurter Allgemeine Zeitung of August 23rd, for example, we can read:

Today we humans are increasingly overwhelmed. Too much information, too much data, too many media [emphasis added], too little time. Computers promise help here, machine learning is the magic word that today provides us with the solution to a variety of problems. (Anderl 2017, 9)

At the same time, and this is particularly interesting, the large amounts of data are also a prerequisite for "machine learning", as Alpaydin emphasizes (Alpaydin 2016, x).

So far, so good. However, this leaves the question unanswered as to why so much data is accumulated at all. It is difficult to state an inner-media logic of escalation here because it is not enough to say that memory is cheap now - you do not have to record user data all the time. There are various reasons for this, such as political reasons (like the NSA), but above all commercial ones - think of the data collections of Google and Facebook:

Artificial intelligence has been researched at universities for decades. Now the discipline makes gigantic jumps, also because there is more money in the game. Much more money. Google and Facebook have raised the stakes to hundreds of millions of dollars. The duel between the data companies serves as an accelerator for research on learning machines. (Brühl and Tanriverdi 2016)

\section{AI and social form: What is media culture?}

The spread of various forms of artificial intelligence is ultimately economically motivated. Apparently, the media culture of artificial intelligence is related to the economic form of society. A medial logic alone does not seem to be sufficient for the explanation. Rather, this finding confirms that the explanation of a "media culture" requires an interdisciplinary approach, that sociological, economic, media-theoretical and informational perspectives must be used to describe the co-constitution of media technologies and social practices. Research 
of this kind on AI and robotics has been done for a long time, for example, in American STS: Langdon Winner critically discusses the discourses on "Autonomous Technologies" in 1977, Steve Woolgar writes an article with the programmatic title "Why not a Sociology of Machines?" in 1985, Harry Collins contributes an article in a handbook entitled "Science Studies and Machine Intelligence" and later Lucy Suchman will write "Feminist STS and the Sciences of the Artificial" for another handbook (Winner 1977; Woolgar 1985; Collins 1995; Suchman 2008).

All this different research deals with the way in which technologies of artificial intelligence (and also robotics) are socially constructed. And this is particularly evident in the media culture of artificial intelligence. Just one example: not explicitly with reference to AI, but with regard to the Internet, which is central to today's machine learning processes of many everyday AI applications, Bill Gates announced back in 1995

When Adam Smith described the concept of markets in The Wealth of Nations in 1776, he theorized that if every buyer knew every seller's price, and every seller knew what every buyer was willing to pay, everyone in the "market" would be able to make fully informed decisions and society's resources would be distributed efficiently. To date we haven't achieved Smith's ideal because would-be buyers and would-be sellers seldom have complete information about one another. [...] The information highway will extend the electronic marketplace and make it the ultimate go-between, the universal middleman. (Gates 1995, 105)

Here, the programmatic approach becomes clear: By means of data accumulation, if not "complete," but at least far-reaching information can be assembled, allowing the penetration of nearly everything with the market form. The ideal market, which is characterized by transparency, should now become real - and the subjects must, therefore, become transparent. Their transparency is more important than their discipline. The opacity of the private sphere, indeed of consciousness, are barriers to the market that are to be dismantled. From this point of view, both the data accumulation and the AIs, which are supposed to help to control and evaluate those, have a clear economic function. Alexa can be described as the intrusion of artificial advertising, but also as a spy and market researcher into the living room. Alexa becomes an artificial family member who acquires trust in communication and thus connects internal family communication with the "joys of marketing", to use a phrase by Gilles Deleuze $(1992,7)$. The fact that an AI can produce unexpected results has precisely the function of generating new desires for products from user data. Gendering, whose asymmetry seems to be inseparable from capitalism - if it is allowed to use this word - is also evident: not only the name "Alexa", but also the femininity of the standard voice. We here find an infrastructural, synthetic care practice. ${ }^{1}$ If one can speak of a "media culture" in everyday practices with artificial intelligence it seems (in large parts) to be a media culture that is decisively shaped by the social form of capitalism.

1 Gender and Capitalism is a difficult topic, see for example: Scholz (2009). 


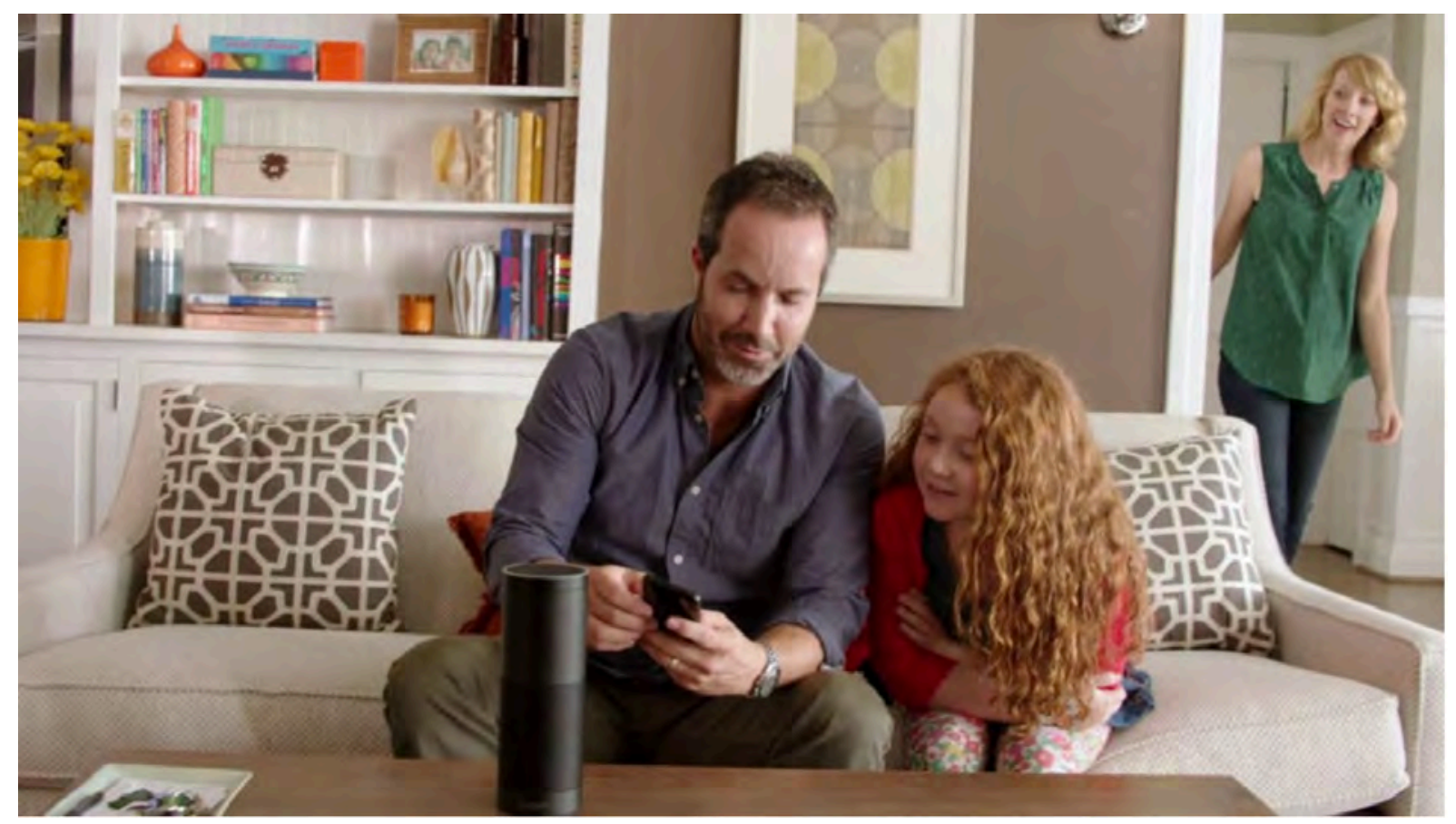

[Fig. 2] Alexa as (female) member of the family (Source:

https://www.heise.de/newsticker/meldung/Alexa-persoenlich-Amazons-

Sprachassistentin-unterscheidet-Benutzer-3858853.html, Accessed January 20, 2018)

But this leads to a theoretical problem. If the media culture of artificial intelligence - at least in the form in which it appears in everyday life, e. g. Alexa - is so instrumental in a certain social structure, in this case, the capitalist market, does it make sense to talk about a media culture at all? After all, the media logic, the processing of information, does not seem to possess any momentum of its own, but rather to be at the service of the market. But it has always been the purpose of media theories to emphasize the non-neutral, formative power of media: Sybille Krämer noted that in the "diversity of media-related research [...] a common denominator" emerges: "This is the conviction that media must not only be involved in the transmission of the messages, but also form the content of the messages itself" (Krämer 1998, 73). Emphasizing the integration of artificial intelligence into a logic of capital seems to override media logic and thus render the concept of media culture superfluous.

Unless - and this would be a media-theoretical twist - capitalism itself would be described as a media culture. How can we describe the form of capitalism? In the following, we will simplify: neither exchange value vs. utility value or surplus value production, nor the question of the connection between increased productivity and work, nor that of market and state, nor the intrinsic and external crises of this economic order (at least as diagnosed by many), and much more can be discussed here (Ingham 2008). With Karl Marx, however, it can be emphasized that a decisive form of capitalism is separate private production.

Individual persons or individual companies produce and then see if they can sell their goods on the market. It is an ex post-mediation between the producers - which is coordinated by price signals. Money is the medium that carries these signals. Money is invested to produce goods that are sold for more money. Marx has argued that the production of value in the form of money - and not the production of goods and the supply of people - is the central 
principle of capitalism (Marx 1976). That might be wrong and has been criticized often enough. Nevertheless, one aspect interests us here: Capitalism could be described as a media culture insofar as it is centered around the medium of money.

Money is invested, e. g. in the development of artificial intelligence applications to generate more money - otherwise, Amazon would not do that. ${ }^{2}$ Admittedly: whether money is a medium or rather a commodity, or whether both perspectives are not ultimately translatable in one another, is the subject of a discussion we cannot go into here (Ingham 2005). But if you accept that thought, you could say: assuming the medial logic of artificial intelligence to be subordinate to the logic of capital would not mean suppressing the mediality at all, but rather exposing a more fundamental mediality. And is the excessive accumulation of data at the same time a condition and reason for machine learning - not exceptionally similar to the accumulation of capital described by Marx? The escalation of the media that Kittler describes, as well as Paul Virilio's emphasis on medial and technological acceleration (Virilio 1986), can be understood as expressions of a logic of escalating accumulation and acceleration inherent to the media culture of capitalism.

However, this theoretical perspective creates a new problem: For what is not really subject to this logic of capital in capitalism, which is precisely why capitalism is called capitalism? If one describes the coupling to the medium of money as a media culture, then simply everything, or at least a lot of things, would be "media culture" today - and the concept would lose its discriminatory power. The problem can also be generalized theoretically: Media theories, which assume a formative power of the media, face the problem that every culture, understood as a connection of discourse and practice forms, is shaped by media. The culture of cooking would not exist without recipe collections and cookbooks, product information in diverse media formats, instructions for cookers and microwaves (which can be understood as media of cooking knowledge in their own particular way). Today cooking culture is probably not available without digital information like chefkoch.de. Therefore, media theories, which as media theories give media a central role, must understand every culture as a media culture. The concept of media culture becomes indistinguishable from the concept of culture in general - and once again superfluous.

In order to be distinguishable from other cultures, media culture would then have to be limited to, for example, fan cultures that are resolutely focused on the products of mass media, i.e. techno-institutional complexes that are conventionally called "the media" in the same way as, for example, art or business or politics. From a media-cultural science point of view, however, such a perspective is too narrow. But there is one more way: one could say that every culture is based on media in the sense of technologies for the storage, transmission, processing, and presentation of information, as well as the practices associated with them - but one can only meaningfully talk about media culture when this mediality itself becomes reflexive, when it is negotiated in conflicts, when it comes - in the sense of Latour - to controversies (Latour 2005). In such processes - and by no means solely by

2 This phrasing is not supposed to obscure the complexities of technological innovation and development and especially not supposed to lead to the impression that innovation is done by huge companies alone. There is a huge amount of literature on that, see just recently: Mazzucato (2015), who underlines the central role the state plays in the development of high-tech. See also: Flichy (2007). 
malfunctions or disturbances - the media, invisible under normal conditions, become themselves visible and disputable.

This brings us back to the example that was used as an introduction to the problem: Let us assume once again that one could see potentially everyday systems such as Alexa (as happened above) in connection with the penetration of everyday life and private space by the logic of exploitation and surveillance - then it becomes surprisingly apparent that the formation of new technologies through the social form of capitalism (or the media culture of money) does not seem to be completely undisturbed, hegemonic and monolithic. Even with examples like Alexa and Siri, the question of whether artificial intelligence might not come into conflict with the form of capitalism has recently been discussed. The argument is usually that AI and the robotics associated with it make so much work superfluous that at some point in time it will become impossible to uphold the reproduction of society via labor, wages, goods form, money and markets - all kinds of solutions from unconditional basic income via machine tax to fully automated luxury communism are discussed.

Of course, all this is also denied and these rejections are criticized again. This discussion, which leads back to important intermediate stations like Hannah Arendt, Norbert Wiener, John Maynard Keynes to at least Marx' famous Maschinenfragment, even to Aristotle to some extent, cannot be presented here. ${ }^{3}$ What is crucial, however, is that this controversy rages again today in relation to AI. For example, the MIT economist Daron Acemoglu (together with Pascual Restrepo) concludes in a major study:

In this respect, we believe as well that the negative effects we estimate are both interesting and perhaps somewhat surprising, especially because they indicate a very limited set of offsetting employment increases in other industries and occupations. (Acemoglu and Restrepo 2017, 37)

Andrew Ng, who co-founded and co-directed the Google Brain Project for deep learning techniques with Jeff Dean at Google, notes in critical dissociation of doomsday fantasies à la Elon Musk, according to whom the AIs will soon take over world domination as terminators: "I think job losses are a big problem and I wish we would focus on that rather than be distracted by these dystopian elements similar to science fiction" (FAZ 2017, 21). Of crucial importance are two points: 1 ) $\mathrm{Ng}$ refers to the role that semantics, borrowed from media culture, have in dealing with the controversies surrounding the new media technology ("dystopian science fiction") and 2) his contribution is just one of many examples for the lively discussion about whether there is a separate media logic of AI, namely: an autonomous processing of information, which can come into conflict with the logic of money as a central medium of capitalism. In this respect, the Durkheim test, which Susan Leigh Star considered decisive for AI - i.e. the question of how it affects "community work" (Star 1989) - is currently the subject of constant discussion in the mass media, including fictional formats.

${ }^{3}$ For an overview see: Schröter (in press). 


\section{Conclusion}

We have tried to use a current example, i.e. the diffusion of artificial intelligence in everyday practices and discourses and asked 1 ) whether AI potentially has a medial logic and 2) how this medial logic is related to social or another medial logic. Is the medial logic of data accumulation - and therefore the need for certain forms of machine learning - merely an effect of the logic of capital? Or is it a logic of its own that can come into conflict with it, as the discussion about the future of work suggests? Apparently, this question (and other questions) are being negotiated - one could draw from this the media-theoretical insight that the question, which is repeatedly asked over and over again, whether medial logic shapes social structures or vice versa, simply cannot be answered generally, not even by a general reference to a co-construction of "users and technology" (Oudshoorn and Pinch 2003). Rather, media culture is precisely the place of these heterogeneous, plural and political conflicts. Therefore "digital culture" is not named "digital culture" because it is based on digital technologies, but it is called that because it comprises of endless negations and controversies what effects the "digital" exactly has and what is "digital" about the "digital culture" at all. 


\section{References}

Acemoglu, Daron, and Pascual Restrepo. 2017. "Robots and Jobs: Evidence from US Labor Markets." Accessed January 20, 2018. https://economics.mit.edu/files/12763.

Alpaydin, Ethem. 2016. Machine Learning: The New AI. Cambridge, MA: MIT Press.

Anderl, Sibylle. 2017. "Undurchsichtige Intelligenzen.", Frankfurter Allgemeine Zeitung, August 23.

Brühl, Jannis and Hakan Tanriverdi. 2016. "Wie Google und Facebook Computern Denken beibringen." Süddeutsche Zeitung, March 1. Accessed January 20, 2018.

http://www.sueddeutsche.de/digital/kuenstliche-intelligenz-wie-google-und-facebook-computerndenken-beibringen-1.2885204.

Collins, Harry. 1995. "Science Studies and Machine Intelligence." In Handbook of Science and Technology Studies, edited by James Petersen, Trevor Pinch, Sheila Jasanoff, and Gerald Markle, 286-301. Thousand Oaks: Sage Publications.

Deleuze, Gilles. 1992. "Postscript on the Societies of Control." October 59: 3-7.

FAZ. 2017. "Streit zwischen Mark Zuckerberg und Elon Musk: Wer hat recht?." Frankfurter Allgemeine Zeitung, July 27.

Flichy, Patrice. 2007. Understanding Technological Innovation: A Socio-technical Approach. Cheltenham: Edward Elgar Publishing.

Gates, Bill. 1995. The Road Ahead. Accessed January 20, 2018.

http://www.guruslodge.com/threads/the-road-ahead-by-bill-gates-pdf-epub-mobi.32045.

Ingham, Geoffrey, ed. 2005. Concepts of Money: Interdisciplinary Perspectives from Economics, Sociology and Political Science. Cheltenham: Edward Elgar Publishing.

Ingham, Geoffrey. 2008. Capitalism. Cambridge: Polity Press.

Kittler, Friedrich. 1993. Draculas Vermächtnis: Technische Schriften. Leipzig: Reclam.

Kittler, Friedrich. 1996. "The History of Communication Media." ctheory Special Issues: Global Algorithm. Accessed January 20, 2018. http://www.ctheory.net/articles.aspx?id=45.

Kittler, Friedrich. 1999. "On the Implementation of Knowledge: Toward a Theory of Hardware." Nettime. Accessed January 20, 2018. http://heavysideindustries.com/wp-

content/uploads/2012/11/On-the-Implementation-of-Knowledge-Toward-a-Theory-of-Hardware.pdf.

Krämer, Sybille. 1998. "Das Medium als Spur und als Apparat." In Medien Computer Realität: Wirklichkeitsvorstellungen und Neue Medien, edited by Sybille Krämer, 73-94. Frankfurt am Main: Suhrkamp.

Lämmel, Uwe, and Jürgen Cleve. 2008. Künstliche Intelligenz. München: Hanser.

Latour, Bruno. 2005. Reassembling the Social: An Introduction to Actor-Network-Theory. Oxford: Oxford University Press.

Marx, Karl. 1976. Capital: A Critique of Political Economy: Volume 1. London: Pelican Books.

Mazzucato, Mariana. 2015. The Entrepreneurial State: Debunking Public vs. Private Sector Myths. New York: Public Affairs.

Oudshoorn, Nelly, and Trevor J. Pinch, eds. 2003. How Users Matter: The Co-construction of Users and Technology. Cambridge, MA: MIT Press.

Scholz, Roswitha. 2009. "Patriarchy and Commodity Society: Gender without the Body" In Marxism and the Critique of Value, edited by Neil Larsen, Mathias Nilges, Josh Robinson, and Nicholas Brown, 123-143. Chicago: MCM.

Schröter, Jens. "Digitale Medientechnologien und das Verschwinden der Arbeit." In Die Maschine: Freund oder Feind? Mensch und Technologie im digitalen Zeitalter, edited by Caja Thimm and Thomas Bächle. Wiesbaden: VS Verlag für Sozialwissenschaften, (in press). 
Star, Susan Leigh. 1989. "The structure of Ill-structured Solutions: Boundary Objects and Heterogeneous Distributed Problem Solving." In Distributed Artificial Intelligence: Vol. 2, edited by Les Gasser and Michael N. Huhns, 37-54. London: Pitman.

Stöcker, Christian. 2016. "Go-Turnier Mensch gegen Maschine: 'Spielzüge, die ein Mensch nie machen würde'." Spiegel Online, March 10. Accessed January 20, 2018.

http://www.spiegel.de/netzwelt/gadgets/google-software-alphago-spielzuege-die-ein-mensch-niemachen-wuerde-a-1081652.html.

Suchman, Lucy. 2008. "Feminist STS and the Sciences of the Artificial." In The Handbook of Science and Technology Studies, edited by Edward J. Hackett, Olga Amsterdamska, Michael Lynch, and Judy Wajcman, 139-64. Cambridge, MA: MIT Press.

Virilio, Paul. 1986. Speed and Politics: An Essay on Dromology. New York: Semiotext(e).

Winner, Langdon. 1977. Autonomous Technology: Technics-out-of-control as a Theme in Political Thought. Cambridge, MA: MIT Press.

Woolgar, Steve. 1985. "Why not a Sociology of Machines? The Case of Sociology and Artificial Intelligence." Sociology 19 (4): 557-72. 